Neurology June 2009;72;e114). (Response and reprints: Dr John Koury, 900 Walnut St, Ste 200, Philadelphia, PA 19107. E-mail: jskhoury@gmail.com).

COMMENT. Dancing as a form of epilepsy is a complex automatism, such as running (epilepsia cursiva) or bicycling movements. Lennox WG, in his book on epilepsy (1960;page 260) refers to episodes of running, spinning round and around, in seizures following head injury.

\title{
CHANGING TRENDS IN ANTIEPILEPTIC DRUG USAGE IN GIRLS
}

Concerns about potential effects on offspring have prompted a gradual change in antiepileptic drug usage in girls of child-bearing age in the last decade, according to a study at the School of Pharmacy and Institute of Child Health, University of London, UK. More females aged 12-18 years are prescribed lamotrigine (LTG) than carbamazepine or sodium valproate, and the 10 -fold increase in LTG in females is significantly greater than the 5 -fold rise for males. (Ackers R, Besag FMC, Wade A, Murray ML, Wong ICK. Arch Dis Child 2009;94:443-447) (Respond: Ian Wong. E-mail: ian.wong@pharmacy.ac.uk).

\section{MOVEMENT DISORDERS}

\section{CLINICAL AND GENETIC ANALYSIS OF MYOCLONUS-DYSTONIA}

Eighty-six myoclonus-dystonia (M-D) index patients from the Dutch national referral center underwent clinical and genetic evaluation in a study at University of Amsterdam, and other centers in the Netherlands and Belgium. Age of onset was $1-18$ years in $48(56 \%)$ and during adulthood in the remainder. Based on clinical examination, 24 cases were classified as definite M-D, 23 were probable, and 39 possible cases. According to previously published criteria, definite M-D had early onset and a positive family history. In the definite group, $50 \%$ carried an SGCE mutation; in the probable group, $4 \%$; and in the possible cases, none had the mutation. (Ritz K, Gerrits MCF, Foncke EMJ, et al. Myoclonus-dystonia: clinical and genetic evaluation of a large cohort. J Neurol Neurosurg Psychiatry June 2009;80:653658). (Respond: Dr MAJ Tijssen, Department of Neurology, Academic Medical Centre, University of Amsterdam, PO Box 22660, 1100 DD Amsterdam, The Netherlands. E-mail: m.a.tijssen@amc.uva.nl).

COMMENT. Myoclonus-dystonia is a genetically heterogeneous movement disorder with autosomal dominant inheritance. The clinical manifestations are myoclonus and dystonia predominantly in the upper body, and in adults may respond to alcohol. A mild dystonia often presents as cervical dystonia or writer's cramp; the myoclonus is rhythmic or arrhythmic, bilateral, asymmetric, involving mainly the proximal arms and axial muscles. The major gene locus maps to the epsilon-sarcoglycan gene (SGCE, DYT11) on chromosome 7q21-22. Various SGCE mutations are reported in several families and sporadic cases. In $50 \%$ cases of M-D, no mutation is identified. 